\title{
Calculations of Multicomponent Distillation Column with Multi-Feeds and Side-Streams*
}

\author{
by Takeshi Ishikazva** and Mitsuho Hirata**
}

\begin{abstract}
Summary: A new method is developed for calculations of the multicomponent distillation in complex column having any number of feeds and multi-side streams. This method employs the group relaxation algorithm for the solution of the non-linear material balance equations at unsteady state condition around each stage in the column. The non-linear material balance equations are solved simulianeously for each component, therefore, no matching is required.

The method may will be applied to either ideal system or nonideal system multicomponent distillation to calculate the product distribution and the composition and temperature profles in the complex column, when one specifies the column pressure, the number of plates, the rate, composition and thermal condition of each feed as well as the locations of the feeds plate and the side-streams.

The method may be started with the assumption only that all the liquid compositions on each stage equal to the overall-feed compositions.

Therefore, a great deal of experience and judgment in choosing initial values are unnecessary. And also both distributed and non-distributed components are handled with equal case.

The computational procedure is simple, and numerically stable. Some problems were discussed to demonstrate the feasibility of the method.
\end{abstract}

\section{Introduction}

The calculation of multicomponent separation in complex column such as multi-feeds and multiside streams fractionators has become more and more important in the modern process design. In the recent year, not only in separations of crude oil, but also in non-ideal system, namely, separations in alcohol industries, rigorous calculation of multicomponent separation in complex column with multi-feeds and multi-side streams has been specially required in order to draw very small quantities of a component continuously.

For conventional column having a feed, many computational procedures were developed ${ }^{1 / \sim 4)}$. But there are only a few methods for complex column ${ }^{5)}$ 7). Holland and coworkers ${ }^{4)}$ developed a " $\theta$-method" to couple with the method of Thiele and Geddes for handling both conventional and complex columns. This method is very usefull for conventional column, but for calculations of complex columns with multifeeds and multi-side streams is numerically unstable and thus basically unsuited. On the other hand, the tridiagonal matrix method

* Received December 22, 1971

** Department of Industrial Chemistry, Faculty of Engineering, Tokyo Metropolitan University (2-1-1, Fukazawa, Setagaya-ku, Tokyo, Japan) developed by Wang and Henke ${ }^{7)}$ may be applied to both conventional and complex columns.

This computational procedure is simple, fast and numerically stable. For handling nonideal system that vapor-liquid equilibrium ratio depends on pressure, temperature and liquid compositions, however, the procedure becomes considerably complex.

In the previous paper ${ }^{8}$, we developed a new method for calculations of the multicomponent distillation. This method employs the group relaxation algorithm for the solution of the nonlinear material balance equations at unsteady state condition around each stage in the column.

In this paper, this computational procedure is developed for calculations of the multicomponent distillation in complex column having any number of feeds and multi-side streams. In this method, the non-linear material balance equations are solved simultaneously for each component, therefore, no matching is required.

The method may well be applied to either ideal system or nonideal systems for calculating the product distribution and the composition and temperature profiles in the complex column, when the column pressure, the number of plates, the rate, composition and thermal condition of 
each feed as well as the locations of the feeds and the side-streams are specified.

The method may be started with the assumption only that all the liquid compositions on each stage, including a condenser and a reboiler, equal to the over all feed compositions. Therefore, a great deal of experience and judgment in choosing initial values are not necessary. As no matching is required, both distributed and nondistributed components are handled with equal case. The computational procedure is simple and numerically stable. Some problems were discussed to demonstrate the feasibility of the method.

\section{Mathematical Model}

For the convenience of deriving the general working equations, a hypothetical system as shown in Fig. 1 is considered as the model column with any number of feeds and multi-side streams. This column has $n$ equilibrium plates, and has a condenser (partial or total) at the top and a reboiler at the bottom.

The stages are numbered from top to bottom with the condenser as the zeroth stage and the reboiler as the $n+1$ th stage.

It is assumed that one feed stream $F_{j}$, one

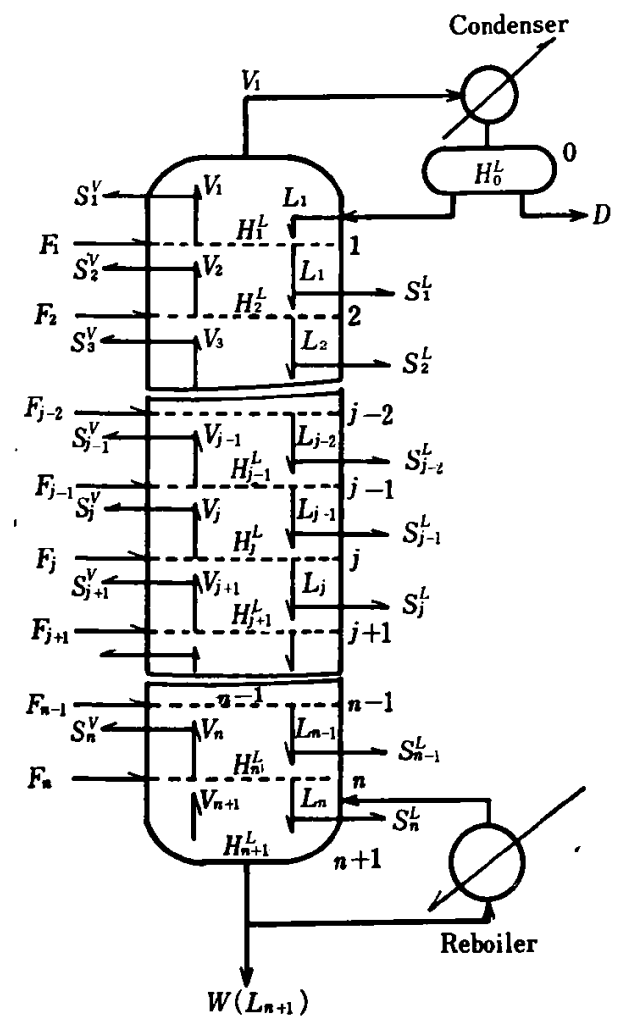

Fig. 1 A Model for the Complex Column vapor side stream $S_{j}{ }^{7}$, and one liquid side stream $S_{j}{ }^{L}$ exist at each stage except for the condenser and the reboiler.

This model column can be reduced to any simpler one by setting the undesired quantities to zero. Thus, for a conventional column all the quantities of the external streams except $F_{f}, D$, and $W$ are zero.

Each stage in the model column is assumed to be an equilibrium stage, that is, the composition of liquid on a stage identical with that of liquid leaving the stage and the vapor stream leaving the stage is in equilibrium with the liquid strcam lcaving the same stage.

Fig. 2 shows such an ideal equilibrium stage except for the condenser and the reboiler.

\subsection{Derivation of Basic Equations}

For the time period or interval from $t$ to $t+$ $1 t$, the component-material balance on the $j$ th stage, except for the condenser and the reboiler, as shown in Fig. 2 is given the integral-difference equation with the law of conservation of mass.

$$
\begin{aligned}
& \int_{t}^{t+\Delta t}\left[\left(F_{j} Z_{F i j}+V_{j+1} y_{i j+1}+L_{j-1} x_{i j-1}\right)\right. \\
& \left.\left.-\left\{\left(V_{j}+S_{j}\right)\right) y_{i j}+\left(L_{j}+S_{j}{ }^{L}\right) x_{i j}\right\}\right] d t \\
& =\left[H_{j} L_{x_{i j}}\right]_{t+\Delta t}-\left[H_{j} x_{i j}\right]_{t}
\end{aligned}
$$

where $j$ refers to the stage number and $i$ refers to the component number. $H_{j}{ }^{2}$ refers to the total moles of the liquid holdup on the $j$ th stage and $V$ and $L$ refer to the vapor and liquid flow rates, respectively.

The vapor holdup, $H_{j} \boldsymbol{V}$, in Fig. 2 is neglected in the material balance because it is usually small relative to the liquid holdup.

By use of the mean value theorem of integral and differential calculus, the left-hand and righthand sides of Eq. (1) may be stated in the following forms, respectively.

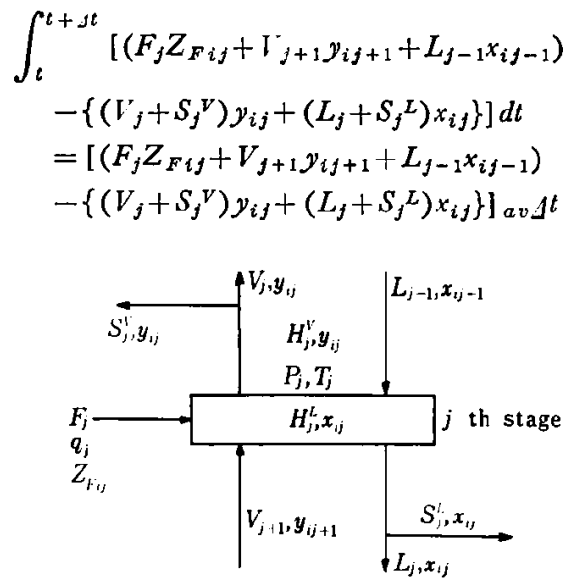




$$
\begin{gathered}
{\left[H_{j} x_{x_{i j}}\right]_{t+\Delta t}-\left[H_{j}^{L} x_{i j}\right]_{t}=\Delta t\left[\frac{d\left(H_{j} x_{x_{i j}}\right)}{d t}\right]_{t+\varepsilon \Delta t}} \\
(0 \leqq \varepsilon \leqq 1)
\end{gathered}
$$

Substituting of Eqs. (2) and (3) into Eq. (1) and it is assumed that the liquid holdup on each stage remained constant with respect to time and also that is considered independent of composition.

Furthermore, by taking the limit of each term as $\Delta t$ approches zero, the following differential material balance for component $i$ on $j$ th stage leads to

$$
\begin{gathered}
H_{j} L\left(\frac{d x_{i j}}{d t}\right)_{t}=\left[\left(F_{j} Z_{F i j}+V_{j+1} y_{i j+1}+L_{j-1} x_{i j-1}\right)\right. \\
\left.-\left\{\left(V_{j}+S_{j}\right) y_{i j}+\left(L_{j}+S_{j}{ }^{L}\right) x_{i j}\right\}\right]_{\iota}
\end{gathered}
$$

For the condenser and the reboiler, similar but slightly different equations can be written as follows, respectively.

$$
\begin{aligned}
& H_{0}{ }^{L}\left(\frac{d x_{i 0}}{d t}\right)_{t}=\left[V_{0} y_{i 0}-L_{0} x_{i 0}-D x_{D i}\right]_{t} \\
& H_{n+1}{ }^{L}\left(\frac{d x_{i n+1}}{d t}\right)_{t}=\left[L_{n} x_{i n}-V_{n+1} y_{i n+1}-W x_{w i}\right]_{t}
\end{aligned}
$$

If all the compositions and the flow rates at time $t$ are known, it is then possible to calculate all the concentration gradients, $d x_{i j} / d t$. However, an implicit form of the finite difference approximation for the differential equation is

$$
\left(\frac{d x_{i j}}{d t}\right)_{t}=\frac{\left(x_{i i}\right)_{t+\Delta t}-\left(x_{i j}\right)_{t}}{\Delta^{t}}
$$

For the convenience of the calculations, consider time $t$ to be iteration $k$ and $t+\Delta t$ to be iteration $k+1$. A combination of Eqs. (4) and (7) leads to,

$$
\begin{gathered}
x_{i j}{ }^{k+1}=x_{i j}{ }^{k}+\mu_{j}\left[\left(F_{j} Z_{F i j}+V_{j+1} y_{i j+1}+L_{j-1} x_{i j-1}\right)\right. \\
\left.-\left\{\left(V_{j}+S_{j}\right) y_{i j}+\left(L_{j}+S_{j} L\right) x_{i j}\right\}\right]^{k}
\end{gathered}
$$

where $\mu_{\rho}$ is the point relaxation factor and is equal to $\left(\Delta t / H_{j}{ }^{L}\right)$.

Furthermore, when the calculation is begun at the top of the column and proceeded downward, instead of $x_{i j-1}{ }^{k}$ in Eq. (8), the values of the liquid compositions of the above stage calculated at $(k+1)$ th iteration, that is, $x_{i j-1}{ }^{k+1}$ were used as the compositions of the $j$-lth stage. Consequently, Eq. (8) may be written as follows ${ }^{9}$.

$$
\begin{gathered}
x_{i j}{ }^{k+1}=x_{i j}{ }^{k}+\mu_{j}\left[F_{j} Z_{F i j}+V_{j+1} y_{i j+1}{ }^{k}+L_{j-1} x_{i j-1}{ }^{k+1}\right. \\
\left.-\left(V_{j}+S_{j}\right) y_{i j}{ }^{k}-\left(L_{j}+S_{j}{ }^{L}\right) x_{i j}{ }^{k}\right]
\end{gathered}
$$

And also by use of the group relaxation algorithm ${ }^{\text {s) }}$, Eq. (9) becomes

$$
\begin{aligned}
& x_{i j}{ }^{k+1}=x_{i j}{ }^{k}+\omega_{i j}{ }^{k}\left[F_{j} Z_{F i j}+V_{j+1} y_{i j+1^{k}}\right. \\
& \quad+L_{j-1} x_{i j-1}{ }^{k+1}-\left(V_{j}+S_{j}\right) y_{i j}{ }^{k} \\
& \left.-\left(L_{j}+S_{j}\right) x_{i j}{ }^{k}\right]
\end{aligned}
$$

where $\omega_{i f}$ is the group relaxation factor and varies in value with respect to component, stage, and iteration. This equation is basic one for the arbitrary stage except for the condenser and the reboiler.

For the condenser and the reboiler, similarly, the following equations are derived, respectively

$$
\begin{gathered}
x_{i 0}{ }^{k+1}=x_{i 0}{ }^{k}+\omega_{i 0}{ }^{k}\left[V_{0} y_{i 0}{ }^{k}-L_{0} x_{i 0}{ }^{k}-D x_{D i}{ }^{k}\right] \\
x_{i n+1}{ }^{k+1}=x_{i n+1}{ }^{k}+\omega_{i n+1^{k}}{ }^{k}\left[L_{n} x_{i n}{ }^{k+1}\right. \\
\left.-V_{n+1} y_{i n+1}{ }^{k}-W x_{W i}{ }^{k}\right]
\end{gathered}
$$

If the equilibrium ratio and the liquid and vapor flow rates are assumed constant from iteration $(k)$ to $(k+1)$, when the liquid composition and flow rates at any iteration $(k)$ are known, by use of Eqs. (10) to (12) the compositions at iteration $(k+1)$ may be calculated, and the process repeated to obtain values for iteration $(k+2)$, and so on. In this calculations, the values of vapor compositions, $y_{i j}$, are obtained from the corresponding values of the liquid compositions, $x_{i j}$, by use of the vapor-liquid equilibrium relation.

\section{Method of Computations}

Assuming constant molal overflow and that the liquid holdup is equal for all the stages of the column, the vapor and liquid flow rates in each stage of the column are given by the following equations

$$
\begin{aligned}
& L_{j}=R D+\sum_{k=1}^{j} F_{k} q_{k}-\sum_{k=1}^{j} S_{k} L \\
& V_{j}=(R+1) D-\sum_{k=1}^{j-1} F_{k}\left(1-q_{k}\right)-\sum_{k=1}^{j} S_{k}^{V}
\end{aligned}
$$

where $R$ is reflux ratio.

One specifies the column pressure, the number of plates, the rate, composition and thermal condition of each feed as well as the locations of the feeds plates and the side-streams. The number of additional specifications which may be made is equal to the total number of streams withdrawn (the distillate, bottoms and sidestreams). For the column containing two liquid side-streams and two vapor side-streams, the additional specifications $R, D, S_{1}{ }^{L}, S_{2}{ }^{L}, S_{1}^{V}$ and $S_{2}{ }^{V}$ may be made. These in turn fix the dependent variable $W$.

In order to make the first trial, temperature and liquid compositions for all the stages of the 
column, and also group relaxation factor for each components are assumed. The calculations may be started with all plate compositions equal to the overall feed composition, but any other starting compositions may be used, and started with group relaxation factors equal to the reciprocal number of two to five times, to avoid distortions and instability in the calculations, the summation of amounts of feeds per unit time.

Use of the basic equations once for each stage gives a new set of liquid compositions on each stage of the column slightly different from those at the start. Repetition of this kind of calculation gives one set after another of liquid compositions, which gradually approach the steady state compositions. In general, most of the compositions change rapidly at first and then gradually approach steady state values. And also the rate of covergence depends considerably on the group relaxation factor assumed and differs from another components.

Accordingly, in order to increase the rate of convergence the group relaxation factors are corrected $^{8)}$.

When the compositions no longer change from one trial to the next and the component material balances are satisfied, steady state solution is obtained to the paticular continuous distillation problem under consideration.

The steady state solution is independent of starting compositions and relaxation factor (corresponding to liquid holdup), but if the real starting composition, holdup, and corresponding flow rates and time lags are used, the calculations describe the approach to steady state.

\section{Computational Procedure}

Computational procedure may be written as follows;

Step 1 Calculate the vapor and liquid flow rates of each stage by use of Eqs. (13) and (14).

Step 2 Assume temperature, liquid compositions and group relaxation factors.

Step 3 Evaluate vapor compositions, $y_{i j}{ }^{k}$, that is in equilibrium with the liquid compositions, $x_{i j}{ }^{k}$.

Step 4 Solve the material balance equation for $x_{i j}{ }^{k+1}$ by using the group relaxation algorithm.

Step 5 Normalize the liquid compositions. Step 6 If the convergence criteria, Eqs. (16) and (17) are satisfied, a convergent solution is obtained. If they are not satisfied, go to step 7. Step 7 Calculate the following convergence criteria,

$$
\xi_{i}=\frac{\left|\sum_{j=1}^{N+1}\left(F_{j} Z_{F i j}-S_{j} L_{x_{i j}}-S_{j}{ }^{v} y_{i j}\right)-D x_{D i}-W x_{W i}\right|}{\sum_{j=1}^{N+1} F_{j} Z_{F i j}}
$$

where $\xi_{i}$ shows how much the material balance of component $i$ is satisfied. The value of $\xi_{i}$ differs largely in each component. Therefore, correction factor for group relaxation factor of each component is calculated by the following equation.

$$
\varphi_{i}=\left|\frac{\log \xi_{k}}{\log \xi_{i}}\right|
$$

where $\xi_{k}$ is the smallest value of $\xi_{i}$.

It is obvious that the larger is the value of $\varphi_{i}$, the less the satisfaction of material balance of component $i$. The values of $\varphi_{i}$ are separated into three groups in order of its value, and each group has one constant $\delta$.

The value of each $\delta$ must be determined taking it into consideration that the group relaxation factor $\omega_{i j}$ should increase and that at the same time the divergence and instability should be avoided as much as posible.

The new factor $\omega_{i j}{ }^{k+1}$ is obtained by multiplying $\omega_{i j}{ }^{k}$ by $\delta$. The values of $\delta$ are finally determined as follows after the experience of a large number of trials, that is,

$$
\begin{array}{lll}
\text { when } & 0 \leqq \varphi_{i} \leqq 0.4 & o=1.0 \\
\text { when } & 0.4<\varphi_{i} \leqq 0.7 & \delta=1.1 \\
\text { when } & 0.7<\varphi_{i} \leqq 1.0 & \delta=1.2
\end{array}
$$

Using the new group relaxation factor, repeat step 3 through step 7 until the desired accuracy is obtained.

\section{Numerical Examples}

This method has been programed for a FACOM 270-30 digital computer at Computer Center of Tokyo Metropolitan University, and many test problems have been successfully solved without relying on special experiences and senses. The convergence criteria used for these problems were;

$$
\frac{\left|\sum_{j=1}^{N+1}\left(F_{j} Z_{F i j}-S_{j}^{L} x_{i j}-S_{j}^{V} y_{i j}\right)-D x_{D i}-W x_{W i}\right|}{\sum_{j=1}^{N+1} F_{j} Z_{F i j} \leqq \varepsilon_{1 i}}
$$


Table 1 Final Results for Example 1

Iteration Number 1226 Where Z-E Refers to $\mathrm{Z} \times 10^{-\mathrm{E}}$

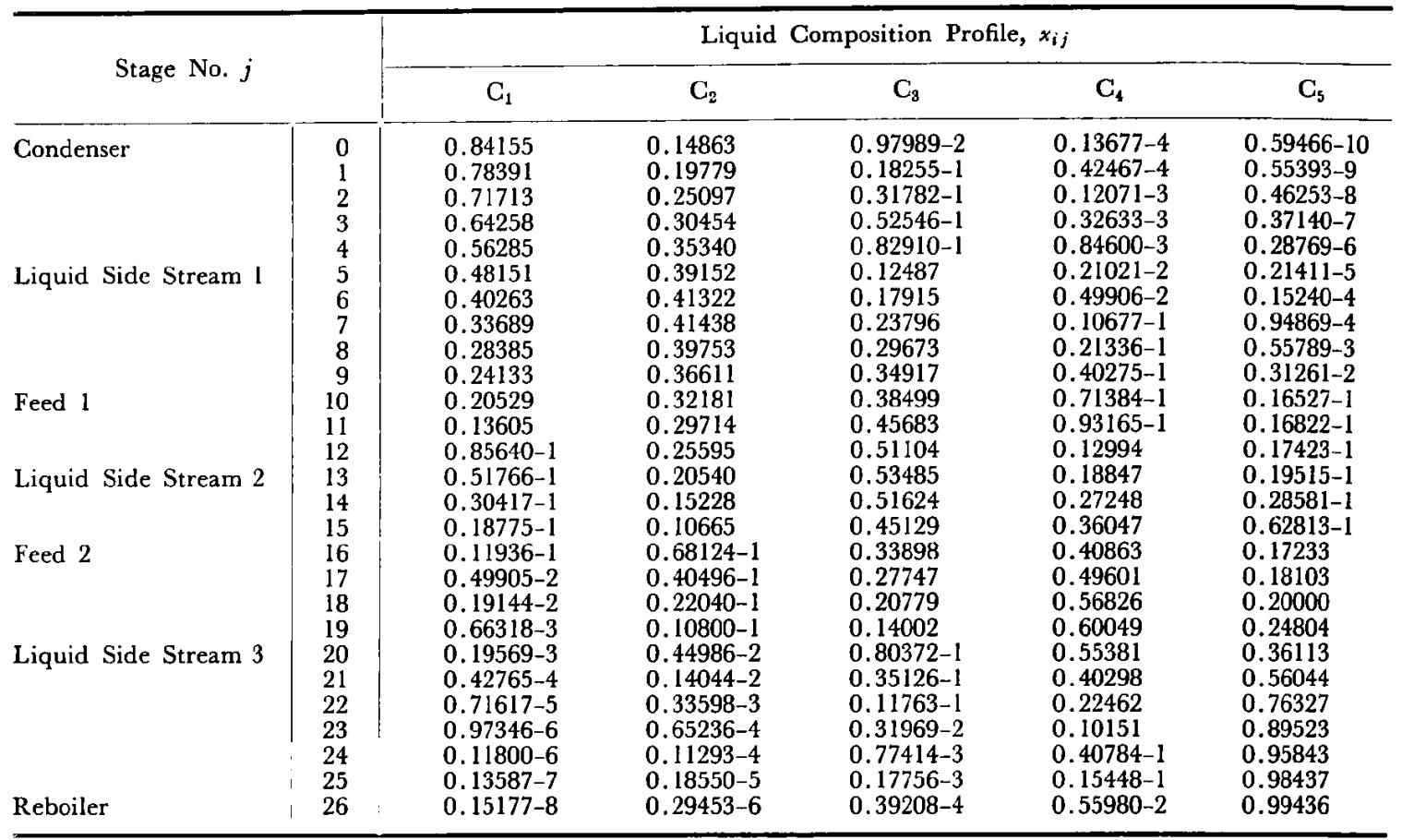

\begin{tabular}{|c|c|c|c|c|c|c|}
\hline \multirow{2}{*}{\multicolumn{2}{|c|}{ Stage No. $j$}} & \multicolumn{5}{|c|}{ Vapor Composition Profile, $y_{i j}$} \\
\hline & & \multirow{2}{*}{$\begin{array}{c}\mathrm{C}_{1} \\
0.88538\end{array}$} & \multirow{2}{*}{$\begin{array}{c}\mathrm{C}_{2} \\
0.10946\end{array}$} & \multirow{2}{*}{$\frac{\mathrm{C}_{3}}{0.51546-2}$} & \multirow{2}{*}{$\frac{\mathrm{C}_{4}}{0.43167-5}$} & \multirow{2}{*}{$\frac{\mathrm{C}_{5}}{0.62563-11}$} \\
\hline Condenser & 0 & & & & & \\
\hline & 1 & 0.84155 & 0.14863 & $0.97989-2$ & $0.13677-4$ & $0.59466-10$ \\
\hline & 2 & 0.78915 & 0.19332 & $0.17487-1$ & $0.39850-4$ & $0.50898-9$ \\
\hline & 3 & 0.72844 & 0.24167 & $0.29783-1$ & $0.11098-3$ & $0.42102-8$ \\
\hline \multirow{6}{*}{ Liquid Side Stream 1} & 4 & 0.66067 & 0.29037 & $0.48660-1$ & $0.29791-3$ & $0.33769-7$ \\
\hline & 5 & 0.58819 & 0.33478 & $0.76265-1$ & $0.77034-3$ & $0.26154-6$ \\
\hline & 6 & 0.51424 & 0.36944 & 0.11441 & $0.19122-2$ & $0.19465-5$ \\
\hline & 7 & 0.44970 & 0.38719 & 0.15882 & $0.42756-2$ & $0.12664-4$ \\
\hline & 8 & 0.39592 & 0.38814 & 0.20694 & $0.89280-2$ & $0.77815-4$ \\
\hline & 9 & 0.35252 & 0.37436 & 0.25502 & $0.17649-1$ & $0.45665-3$ \\
\hline \multirow[t]{3}{*}{ Feed 1} & 10 & 0.31773 & 0.34865 & 0.29793 & $0.33144-1$ & $0.25579-2$ \\
\hline & 11 & 0.22596 & 0.34546 & 0.37937 & $0.46421-1$ & $0.27939-2$ \\
\hline & 12 & 0.15264 & 0.31934 & 0.45543 & $0.69483-1$ & $0.31054-2$ \\
\hline \multirow[t]{3}{*}{ Liquid Side Stream 2} & 13 & $0.99271-1$ & 0.27573 & 0.51283 & 0.10843 & $0.37424-2$ \\
\hline & 14 & $0.63404-1$ & 0.22220 & 0.53804 & 0.17039 & $0.59576-2$ \\
\hline & 15 & $0.43311-1$ & 0.17221 & 0.52053 & 0.24946 & $0.14490-1$ \\
\hline \multirow[t]{4}{*}{ Feed 2} & 16 & $0.32354-1$ & 0.12926 & 0.45940 & 0.33228 & $0.46709-1$ \\
\hline & 17 & $0.14722-1$ & $0.83624-1$ & 0.40928 & 0.43897 & $0.53405-1$ \\
\hline & 18 & $0.61417-2$ & $0.49495-1$ & 0.33330 & 0.54690 & $0.64161-1$ \\
\hline & 19 & $0.23419-2$ & $0.26697-1$ & 0.24722 & 0.63615 & $0.87589-1$ \\
\hline \multirow[t]{6}{*}{ Liquid Side Stream 3} & 20 & $0.79619-3$ & $0.12812-1$ & 0.16350 & 0.67596 & 0.14693 \\
\hline & 21 & $0.21872-3$ & $0.50278-2$ & $0.89823-1$ & 0.61830 & 0.28663 \\
\hline & 22 & $0.47796-4$ & $0.15696-2$ & $0.39254-1$ & 0.44973 & 0.50940 \\
\hline & 23 & $0.80041-5$ & $0.37547-3$ & $0.13143-1$ & 0.25039 & 0.73608 \\
\hline & 24 & $0.10878-5$ & $0.72876-4$ & $0.35683-2$ & 0.11279 & 0.88357 \\
\hline & 25 & $0.13170-6$ & $0.12587-4$ & $0.86060-3$ & $0.44923-1$ & 0.95420 \\
\hline Reboiler & 26 & $0.15006-7$ & $0.20386-5$ & $0.19384-3$ & $0.16606-1$ & 0.98320 \\
\hline
\end{tabular}




$$
\sum_{j=0}^{N+1}\left(x_{i j}{ }^{k+1}-x_{i j}\right)^{2} \leqq \varepsilon_{2}
$$

where $\varepsilon_{1 i}$ and $\varepsilon_{2}$ are a tolerance error, respectively.

The computer running time for the method is proportional to the number of components and the number of stages in the column, regardless of the number of feed streams and the number of side-streams. For the problems tested, the computing time was about 0.001 seconds per component per stage per iteration.

As illustrative examples for the proposed method, the calculations of multicomponent distillation column with multi-feeds and sidestreams are performed in three situations; the first is the case in which vapor-liquid equilibrium ratio is a function of liquid composition only. The second is the case in which the ratio is a function of temperature and pressure, and the third is the case in which the activity coefficient is used to calculate the vapor-liquid equilibrium. Example 1: A complex column with two feeds and three liquid side-streams is considered. A mixture of five components is to be separated at $1 \mathrm{~atm}$. The column has 27 equilibrium stages, including a total condenser and a reboiler. The first feed consisting of 1.0 moles of saturated vapor $(q=0)$ is fed to the 10 th plate, which has the composition: $\mathrm{C}_{1}, 0.50 ; \mathrm{C}_{2}, 0.20 ; \mathrm{C}_{3}, 0.15$; $\mathrm{C}_{4}, 0.10$; and $\mathrm{C}_{5}, 0.05$. The second feed of 1.0 moles of saturated liquid $(q=1.0)$ entered at the 16th plate, which has the composition: $\mathrm{C}_{1}$, $0.05 ; \mathrm{C}_{2}, 0.10 ; \mathrm{C}_{3}, 0.15 ; \mathrm{C}_{4}, 0.20$ and $\mathrm{C}_{5}, 0.50$. Each liquid side-stream of 0.4 moles is to be drawn from the 5th, 13th and 20th plate. Relative volatility of each component gives hypothetically as follows; $\alpha_{15}, 10.0 ; \alpha_{25}, 7.0 ; \alpha_{35}, 5.0 ; \alpha_{45}, 3.0$; and $\alpha_{\overline{0} \bar{j}}, 1.0$. Two other conditions specified are the distillate $D=0.4$ moles and the reflux ratio $R=10.0$.

By assuming that initial group relaxation factors equal to the reciprocal number of five times, that is, 0.1 and starting with using over all feed compositions as initial values of the liquid com-

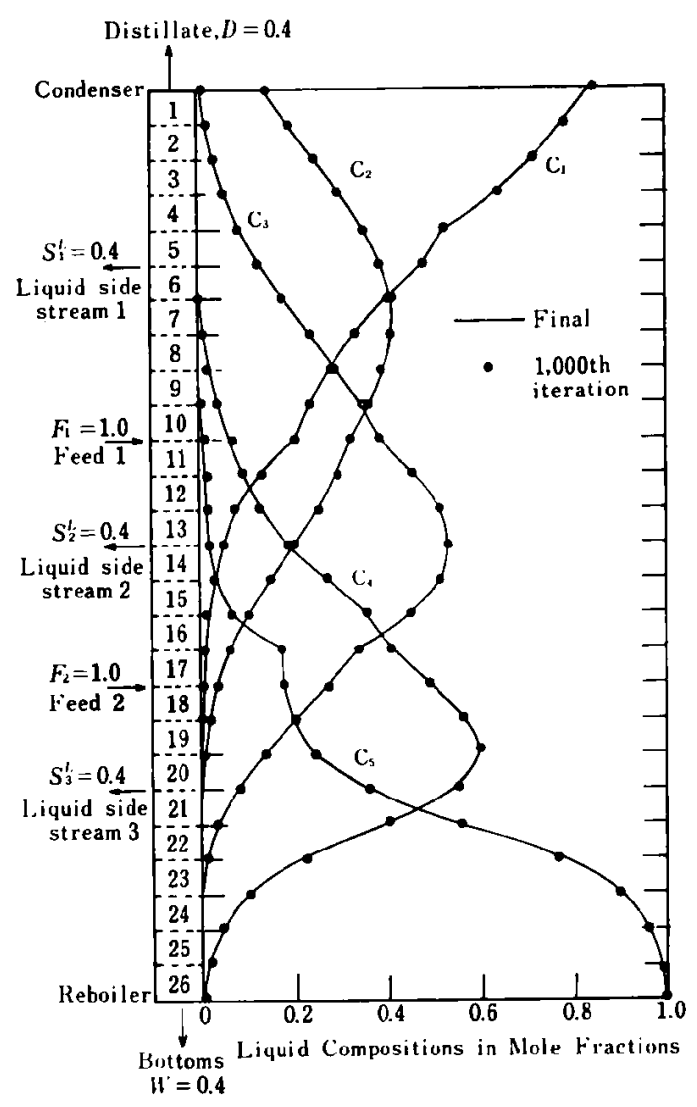

Fig. 3 Liquid Composition Profile of Example 1

positions for all the stages of the column, when $\varepsilon_{1 i}=10^{-4}$ and $\varepsilon_{2}=10^{-6}$, a steady-state solution was obtained in 1226 iterations. In this case, the computing running time, including the printout of input data and detailed results of the final iteration, was about 200 seconds.

Table 1 and Fig. 3 show the liquid and vapor composition profile calculated.

Example 2: A complex column with two feeds and two side-streams is considered. The mixture consisting of benzene(1), toluene(2), $m$-xylene(3), ethylbenzene(4), and cumene(5) is to be separated at atmospheric pressure. The column has 27 equilibrium stages, including a total condenser and a reboiler. The first feed consisting of 1.0 moles of saturated vapor is fed to the 12 th plate. The second feed of 1.0 moles of saturated liquid

Table 2 Feed Conditions and the Physical Data Used for Example 2

\begin{tabular}{l|c|c|cc}
\hline $\begin{array}{l}\text { Condition Feed } \\
\text { Plate Component }\end{array}$ & $\begin{array}{c}\text { Feed 1 } \\
\text { Saturated Vapor } \\
\text { 10, Mole Fraction }\end{array}$ & $\begin{array}{c}\text { Feed 2 } \\
\text { Saturated Liquid } \\
\text { 16, Mole Fraction }\end{array}$ & \multicolumn{3}{|c}{ Cox-Antoine Constants ${ }^{10}$} \\
\hline Benzene (1) & 0.50 & $A_{i}$ & $B_{i}$ \\
Toluene (2) & 0.20 & 0.05 & 6.90565 & $1,211.033$ \\
m-Xylene (3) & 0.15 & 0.10 & 6.94280 & $1,337.63$ \\
Ethylbenzene (4) & 0.10 & 0.15 & 6.95984 & $1,437.37$ \\
Cumene (5) & 0.05 & 0.50 & 6.95423 & $1,422.24$ \\
\hline
\end{tabular}


entered at the 20th plate. From the 7 th and 16th plate, liquid side-streams of each 0.2 moles are to be drawn continuously.

Feeds compositions and the physical data are summarized in Table 2.

Products of 0.6 moles of liquid from total condenser and 1.0 moles of bottoms are to be

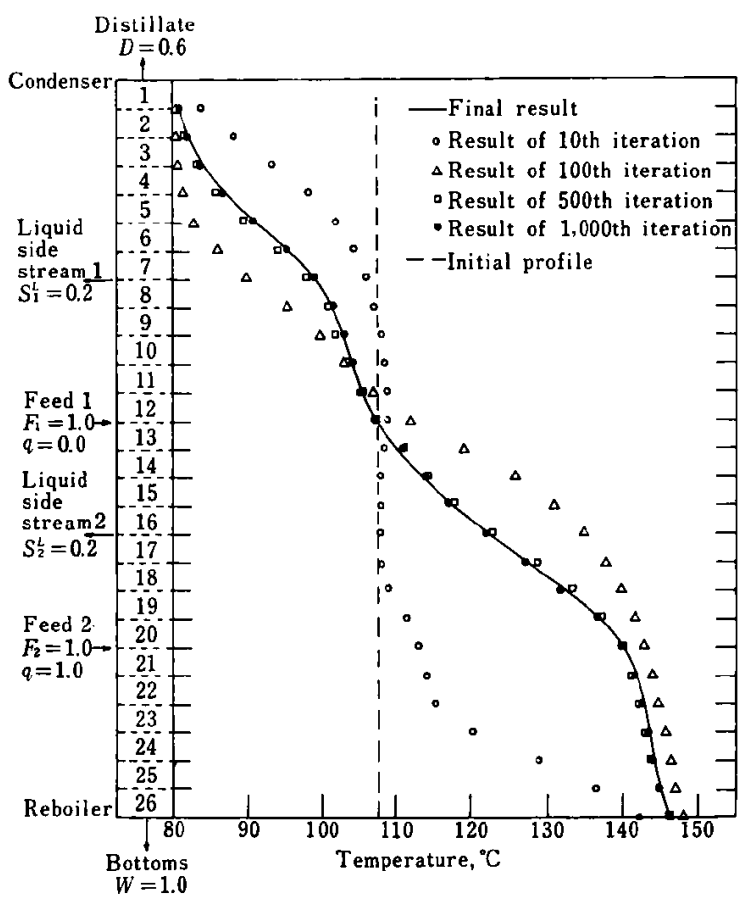

Fig. 4 Temperature Profile for Example 2 obtained. The reflux rate is 3.0 moles $(R=5.0)$. The group relaxation factors are taken as 0.1 mole ${ }^{-1}$. Starting with using overall feed compositions as initial values of the liquid compositions on each stage, a steady state solution

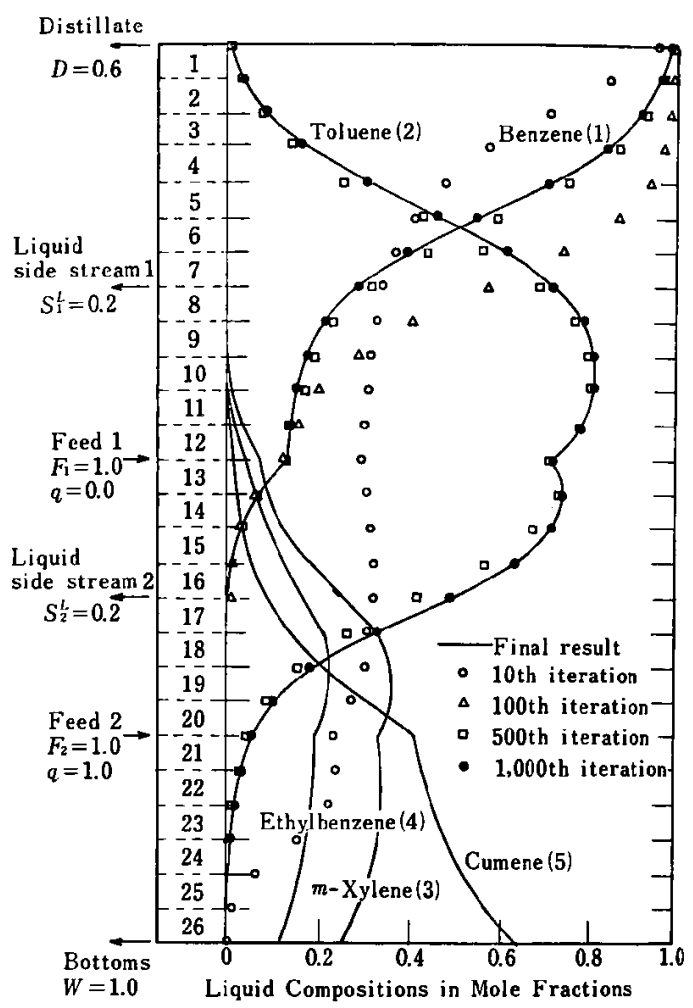

Fig. 5 Liquid Composition Profile of Example 2

Table 3 Results of Example 2

Iteration Number 1200 Where Z-E Refers to $\mathrm{Z} \times 10^{-\mathrm{E}}$

\begin{tabular}{|c|c|c|c|c|c|c|c|}
\hline \multirow{2}{*}{\multicolumn{2}{|c|}{ Stage No. $j$}} & \multirow{2}{*}{$\underset{{ }^{\circ} \mathrm{C}}{\text { Temp. }} T_{j}$} & \multicolumn{5}{|c|}{ Liquid Composition Profile, $x_{i j}$} \\
\hline & & & Benzene & Toluene & $m$-Xylene & Ethylbenzene & Cumene \\
\hline \multirow[t]{6}{*}{ Condenser } & 0 & 80.50 & 0.9843 & $0.1557-1$ & $0.6638-7$ & $0.1019-6$ & $0.1246-9$ \\
\hline & $\begin{array}{l}1 \\
2\end{array}$ & $\begin{array}{l}80.89 \\
81.88\end{array}$ & $\begin{array}{l}0.9606 \\
0.9134\end{array}$ & $\begin{array}{l}0.3938-1 \\
0.8660-1\end{array}$ & $\begin{array}{l}0.4213-6 \\
0.2214-5\end{array}$ & $\begin{array}{l}0.5953-6 \\
0.2887-5\end{array}$ & $\begin{array}{l}0.1261-8 \\
0.1043-7\end{array}$ \\
\hline & 3 & 83.74 & 0.8283 & 0.1717 & $0.1058-4$ & $0.1272-4$ & $0.7867-7$ \\
\hline & 4 & 86.81 & 0.6979 & 0.3020 & $0.4490-4$ & $0.4977-4$ & $0.5251-6$ \\
\hline & 5 & 90.98 & 0.5396 & 0.4601 & $0.1637-3$ & $0.1674-3$ & $0.2988-5$ \\
\hline & 6 & 95.41 & 0.3919 & 0.6071 & $0.5105-3$ & $0.4824-3$ & $0.1441-4$ \\
\hline \multirow[t]{5}{*}{ Liquid Side Stream 1} & 7 & 99.08 & 0.2831 & 0.7142 & $0.1404-2$ & $0.1226-2$ & $0.6086-4$ \\
\hline & 8 & 101.60 & 0.2156 & 0.7778 & $0.3548-2$ & $0.2866-2$ & $0.2350-3$ \\
\hline & 9 & 103.11 & 0.1799 & 0.8050 & $0.8183-2$ & $0.6130-2$ & $0.8184-3$ \\
\hline & 10 & 104.16 & 0.1610 & 0.8059 & $0.1795-1$ & $0.1247-1$ & $0.2712-2$ \\
\hline & 11 & 105.29 & 0.1491 & 0.7803 & $0.3771-1$ & $0.2428-1$ & $0.8615-2$ \\
\hline \multirow[t]{4}{*}{ Feed 1} & 12 & 107.12 & 0.1378 & 0.7177 & $0.7442-1$ & $0.4443-1$ & $0.2567-1$ \\
\hline & 13 & 110.94 & $0.7041-1$ & 0.7478 & $0.9372-1$ & $0.5964-1$ & $0.2839-1$ \\
\hline & 14 & 113.99 & $0.3681-1$ & 0.7158 & 0.1276 & $0.8524-1$ & $0.3458-1$ \\
\hline & 15 & 117.36 & $0.2084-1$ & 0.6238 & 0.1821 & 0.1240 & $0.4926-1$ \\
\hline \multirow[t]{4}{*}{ Liquid Side Stream 2} & 16 & 121.78 & $0.1317-1$ & 0.4808 & 0.2542 & 0.1713 & $0.8049-1$ \\
\hline & 17 & 127.22 & $0.9238-2$ & 0.3188 & 0.3242 & 0.2118 & 0.1360 \\
\hline & 18 & 132.42 & $0.7214-2$ & 0.1887 & 0.3634 & 0.2280 & 0.2126 \\
\hline & 19 & 136.68 & $0.6099-2$ & 0.1044 & 0.3650 & 0.2192 & 0.3053 \\
\hline \multirow[t]{6}{*}{ Feed 2} & 20 & 139.93 & $0.5446-2$ & $0.5725-1$ & 0.3362 & 0.1930 & 0.4081 \\
\hline & 21 & 141.66 & $0.1562-2$ & $0.3512-1$ & 0.3430 & 0.1928 & 0.4275 \\
\hline & 22 & 142.75 & $0.4377-3$ & $0.2088-1$ & 0.3419 & 0.1871 & 0.4497 \\
\hline & 23 & 143.61 & $0.1204-3$ & $0.1206-1$ & 0.3331 & 0.1766 & 0.4781 \\
\hline & 24 & 144.41 & $0.3243-4$ & $0.6718-2$ & 0.3157 & 0.1613 & 0.5162 \\
\hline & 25 & 145.32 & $0.8466-5$ & $0.3546-2$ & 0.2881 & 0.1409 & 0.5674 \\
\hline Reboiler & 26 & 146.39 & $0.2052-5$ & $0.1702-2$ & 0.2489 & 0.1155 & 0.6340 \\
\hline
\end{tabular}


Table 4 Results of Example 3

Iteration Number 629 Where Z-E Refers to $\mathrm{Z} \times 10^{-\mathrm{E}}$

\begin{tabular}{|c|c|c|c|c|c|c|}
\hline \multirow{2}{*}{\multicolumn{2}{|c|}{ Stage No. $j$}} & \multirow{2}{*}{$\underset{{ }^{\circ} \mathrm{C}}{\text { Temp. }} T_{j}$} & \multicolumn{4}{|c|}{ Liquid Composition Profile, $x_{i j}$} \\
\hline & & & Methanol & Ethanol & Water & Propanol \\
\hline \multirow[t]{4}{*}{ Condenser } & 0 & 67.21 & 0.79241 & 0.18750 & $0.19888-1$ & $0.16048-3$ \\
\hline & 1 & 68.57 & 0.68677 & 0.27587 & $0.36826-1$ & $0.53041-3$ \\
\hline & 2 & 70.12 & 0.57186 & 0.36699 & $0.59637-1$ & $0.15088-2$ \\
\hline & $\begin{array}{l}3 \\
4\end{array}$ & $\begin{array}{l}71.69 \\
73.13\end{array}$ & $\begin{array}{l}0.46168 \\
0.36700\end{array}$ & $\begin{array}{l}0.44738 \\
0.50627\end{array}$ & $\begin{array}{l}0.87073-1 \\
0.11768\end{array}$ & $\begin{array}{l}0.38614-2 \\
0.90511-2\end{array}$ \\
\hline \multirow[t]{4}{*}{ Liquid Side Stream 1} & 5 & 74.40 & 0.29202 & 0.53763 & 0.15071 & $0.19639-1$ \\
\hline & $\begin{array}{l}6 \\
7\end{array}$ & $\begin{array}{l}75.55 \\
76.66\end{array}$ & $\begin{array}{l}0.23549 \\
0.19621\end{array}$ & $\begin{array}{l}0.83885 \\
0.51129\end{array}$ & $\begin{array}{l}0.18607 \\
0.22083\end{array}$ & $\begin{array}{l}0.39588-1 \\
0.71674-1\end{array}$ \\
\hline & 8 & 77.83 & 0.16838 & 0.46074 & 0.25274 & $\begin{array}{l}0.71684-1 \\
0.11814\end{array}$ \\
\hline & 9 & 79.11 & 0.14806 & 0.39685 & 0.27698 & 0.17811 \\
\hline \multirow[t]{5}{*}{ Feed 1} & 10 & 80.42 & 0.13327 & 0.33242 & 0.28584 & 0.24847 \\
\hline & 11 & 81.83 & $0.91808-1$ & 0.30274 & 0.31180 & 0.29362 \\
\hline & 12 & 83.13 & $0.61840-1$ & 0.26245 & 0.33344 & 0.34227 \\
\hline & 13 & 84.26 & $0.40987-1$ & 0.21837 & 0.35029 & 0.39036 \\
\hline & 14 & 85.20 & $0.26864-1$ & 0.17591 & 0.36267 & 0.43456 \\
\hline \multirow[t]{6}{*}{ Liquid Side Stream 2} & 15 & 85.94 & $0.17442-1$ & 0.13811 & 0.37135 & 0.47310 \\
\hline & 16 & 86.51 & $0.11177-1$ & 0.10600 & 0.37725 & 0.50557 \\
\hline & 17 & 86.91 & $0.72125-2$ & $0.80806-1$ & 0.38084 & 0.53114 \\
\hline & 18 & 87.20 & $0.46800-2$ & $0.61305-1$ & 0.38237 & 0.55165 \\
\hline & 19 & 87.41 & $0.30501-2$ & $0.46418-i$ & 0.38016 & 0.57036 \\
\hline & 20 & 87.57 & $0.20075-2$ & $0.35585-1$ & 0.36541 & 0.59700 \\
\hline Reboiler & 21 & 87.77 & $0.13749-2$ & $0.29338-1$ & 0.29841 & 0.67088 \\
\hline
\end{tabular}

was obtained in 1,200 iterations. Table $\mathbf{3}$ and Figs. 4 and 5 give the computational results of this example. As shown in Figs. 4 and 5, the result obtained at the end of the 1,000th iteration is close to the final solution and could be considered sufficiently accurate in practical use.

In this problem, when $\varepsilon_{1 i}=10^{-4}$ and $\varepsilon_{2}=10^{-8}$ the computing running time was about 300 seconds, and also when $\varepsilon_{1 i}=10^{-3}$ and $\varepsilon_{2}=10^{-6}$, that was about 200 seconds.

Example 3: Lastly, a complex distillation column with a feed and two liquid sidestreams is considered. The column is operated at 1 atm and the nonideal mixture consisting of methanol (1), ethanol(2), water(3), and propanol(4) is to be separated. The column has 22 equilibrium stages, including a total condenser and a reboiler.

One mole of feed has the composition; methanol, 0.3; ethanol, 0.2; water, 0.2; and propanol, 0.3 . The feed of saturated liquid is entered at the 10th plate numbered from top. The liquid sidestreams of each 0.2 moles are to be drawn from the 5 th plate and 15 th plate.

The physical data used in this problem are given in Reference ${ }^{11)}$. As the activity coefficients-composition equation, Wilson equation was used and Cox-Antoine equation was also used to calculate vapor pressure of pure components. Two other conditions specified are the distillate rate $D=0.3$ moles and the reflux ratio $R=10.0$.

The group relaxation factor is taken as 0.2 .
The calculation is started with liquid of feed composition on each plate and in the condenser and the reboiler. When $\varepsilon_{1 i}=10^{-3}$ and $\varepsilon_{2}=10^{-6}$, a steady state solution was obtained in 629 iterations. Table 4 gives the final profile of liquid composition and temperature only. The computing running time required for this solution, including the printout of input data and detailed results of the final iteration, was about 240 seconds.

\section{Conclusion}

The new method for the calculations of the multicomponent distillation column with multifeeds and multi-sidestreams has been developed. This method employs the group relaxation method for the solution of the non-linear material balance equations. The non-linear equations are solved simultaneously for each component, therefore, no matching is required.

Availability of the method was demonstrated by three numerical examples of different case. As a result of calculations, it is confirmed that this method may be well applied to either ideal system or nonideal system, and also the choice of successive trial values is very simple and special consideration for very small quantities of a component involved product streams (distillate, bottoms, and side-streams) are not necessary. The method converges more stably and relatively rapidly. 


\section{Nomenclature}

$A_{i}, B_{i}, C_{i}:$ Cox-Antoine's constants

$D$ : Distillate product, moles

$F_{j}: \quad$ Feed stream at stage $j$, moles

$H_{j}{ }^{V}$ : Vapor holdup on stage $j$, moles

$H_{j}{ }^{L}: \quad$ Liquid holdup on stage, $j$, mole

$i$ : Component number

$j:$ Stage number

$k$ : Iteration number

$L_{j}$ : Liquid stream flowing the $j$ th stage down to the $(j+1)$ the stage

$n$ : Total number of plates in complex column

$R:$ Reflux ratio

$S_{j} V$ : Vapor side stream from the $j$ th stage, moles

$S_{j} L$ : Liquid side stream from the $j$ th stage, moles

$W$ : Bottom product, moles

$q_{j}$ : Thermal conditions of feed stream at stage $j$

$x_{i j}$ : Compositions of the liquid stream leaving the $j$ th stage, mole fractions

$y_{i j}$ : Compositions of the vapor stream leaving the $j$ th stage, mole fractions

$Z_{F i j}$ : Compositions of the feed stream entering the Greek letters $j$ th stage, mole fractions

$\mu:$ Point relaxation factor

$\omega$ : Group relaxation factor

$\Delta:$ Increment

$\varepsilon:$ Tolerance errors $\varphi$ : Correction factor of relaxation factor

$\alpha$ : Relative volatility

\section{Literature Cited}

1) I.ewis, W. K., Matheson, G. L., Ind. Eng. Chem., 24, 496 (1932).

2) Thiele, E. W., Geddes, R. L., ibid., 25, 290 (1933).

3) Holland, C. D., "Multicomponent Distillation", (1963) Prentice Hall, Englewood Cliffs, N. J.

4) Lyster, W. N., Sullivan, Jr., S. L., Billingsley, D. S., Holland, C. D., Petrol. Refiner., 38, (6), 221; (7) $151 ;(10), 139$ (1959).

5) Amundson, N. R., Potinen, A. J., Ind. Eng. Chem., 50, 730 (1958).

6) Rose, A., Sweeny, R. F., Schrodt, V. N., ibid., 50, 737 (1958).

7) Wang, J. C., Henke, G. E., Hydrocarbon Processing, 45, 155 (1966).

8) Ishikawa, T., Hirata, M., contributed to Soc. Chemical Engineer of Japan.

9) Ishikawa, T., Hirata, M., contributed to Soc. Chemical Engineer of Japan.

10) Dreisbach, R. R., "Physical Properties of Chemical Compounds", 1-111 (1961) Amercian Chemical Society, Washington, D. C.

11) Hirose, Y., Hiraiwa, H., Kagaku Kōgaku, 33, 998 (1968). 